\title{
ON ITERATIVE SOLUTION OF NONLINEAR FUNCTIONAL EQUATIONS IN A METRIC SPACE
}

\author{
RABINDRANATH SEN \\ Department of Applied Mathematics \\ University College of Sclence \\ 92 Acharya Prafulla Chandra Road \\ Calcutta-700009 \\ INDIA \\ and \\ SULEKHA MUKHERJEE \\ Department of Mathematics \\ University of Kalyani \\ Kalyani, Dt. Nadia \\ West Bengal, INDIA \\ (Received September 4, 1981)
}

ABSTRACT. Given that $A$ and $P$ as nonlinear onto and into self-mappings of a complete metric space $R$, we offer here a constructive proof of the existence of the unique solution of the operator equation $A u=P u$, where $u \in R$, by considering the iterative sequence $A u_{n+1}=P u_{n}\left(u_{0}\right.$ prechosen, $\left.n=0,1,2, \ldots\right)$. We use Kannan's criterion [1] for the existence of a unique fixed point of an operator instead of the contraction mapping principle as employed in [2]. Operator equations of the form $A^{n} u=P^{m} u$, where $u \in R$, $\mathrm{n}$ and $\mathrm{m}$ positive integers, are also treated.

KEY WORDS AND PHRASES. Kannan's fixed point theorem, Nonlinear Integral Equation. 1980 MATHEMATICS SUBJECT CLASSIFICATION CODES. Primary: 65J15, 47H17; Secondary: 47 H10.

1. INTRODUCTION.

$R$ is a complete metric space. A is an operator possibly nonlinear mapping $R$ onto R. $P$ is a nonlinear operator mapping $R$ into $R$. We investigate the unique solution of the equation

$$
\mathrm{Au}=\mathrm{Pu}, \quad \mathrm{u} \in \mathrm{R}
$$

by considering the iterates of the form 


$$
\mathrm{Au}_{\mathrm{n}+1}=\mathrm{Pu}
$$

where $u_{0}$ is prechosen and $n=0,1,2,3, \ldots$.

Using the contraction mapping principle, we have proved in [2] the convergence of (1.2). By considering the sequence (m a positive integer, $u_{0}$ prechosen), Chatterjee [3] proved the convergence of $\left\{u_{n}\right\}$ to the unique solution of (1.1). By arguing along the lines of [2], Chakravorty has proved the solvability of the equation $A^{n} u=P^{m} u$ where $u \in R$, $n$ and $m$ are positive integers, as well as the system of simultaneous equations $\mathrm{Au}=\mathrm{Pv}, \mathrm{A}_{1} \mathrm{u}=\mathrm{P}_{1} \mathrm{v}, \mathrm{u}, \mathrm{v} \in \mathrm{R}$.

In this paper we are using Kannan's [1] criterion for the existence of the unique fixed point of an operator to build up a sequence of sufficient conditions which will guarantee the convergence of the sequence (1.2). Conditions for the convergence of $\left\{u_{i}\right\}$ given by $A^{n} u_{i+1}=P^{m} u_{i}\left(n, m\right.$ positive integers, $u_{0}$ prechosen, $\left.i=0,1,2, \ldots\right)$ under suitable conditions to the unique solution of $A^{n} u=P^{m}$ where $u \in \cdot R$ are also formulated. Section 2 contains the convergence theorems. Section 3 contains a nonlinear integral equation where our method can be effectively applied to ensure the existence and uniqueness of the solution of the equation.

2. CONVERGENCE.

We first state Kannan's theorem as follows:

"If $T$ is a map of a complete metric space $E$ into itself and if $\rho[\mathrm{T}(\mathrm{x}), \mathrm{T}(\mathrm{y})] \leq \alpha\{\rho[\mathrm{x}, \mathrm{T}(\mathrm{x})]+\rho[\mathrm{y}, \mathrm{T}(\mathrm{y})]\}$, where $\mathrm{x}, \mathrm{y} \in \mathrm{E}$ and $0<\alpha<\frac{1}{2}$, then $\mathrm{T}$ has a unique fixed point in E".

THEOREM 2.1. Let the following conditions be fulfilled for all $u, v \in R$.

(i) $\beta \rho(\mathrm{u}, \mathrm{v}) \geq \rho(\mathrm{Au}, \mathrm{Av}) \geq \alpha \rho(\mathrm{u}, \mathrm{v}), \quad \beta>\alpha>1$

(ii) $\rho(\mathrm{APu}, \mathrm{Pu}) \leq \gamma \rho(\mathrm{Au}, \mathrm{Pu})$

(iii) $2 \beta \gamma<\alpha(\alpha-1)$

Then the sequence $\left\{u_{n}\right\}$, defined by (1.2), will converge to the unique solution of the equation (1.1).

The error estimate is given by

$$
\rho\left(u_{n}, u^{*}\right) \leq q\left(\frac{q}{1-q}\right)^{n-1} \rho\left(u_{o}, A^{-1} P u_{0}\right), \quad q=\frac{\beta \gamma}{\alpha(\alpha-1)}
$$

PROOF. The existence of $\mathrm{A}^{-1}$, its boundedness and continuity follow from (i). 
Thus, the sequence $\left\{u_{n}\right\}$ where $u_{n}=A^{-1} P_{n-1}, n=1,2, \ldots$, and $u_{0}$ prechosen, is we11defined.

It then follows from (i) and (iii) that, for all $u, v \in P$,

$$
\begin{aligned}
\rho\left(\mathrm{A}^{-1} \mathrm{Pu}, \mathrm{A}^{-1} \mathrm{Pv}\right) & \leq 1 / \alpha \rho(\mathrm{Pu}, \mathrm{Pv}) \\
& \leq 1 / \alpha\left[\rho\left(\mathrm{A}^{-1} \mathrm{Pu}, \mathrm{A}^{-1} \mathrm{Pv}_{\mathrm{v}}+\rho\left(\mathrm{A}^{-1} \mathrm{Pu}, \mathrm{Pu}\right)+\rho\left(\mathrm{A}^{-1} \mathrm{P}_{\mathrm{v}}, \mathrm{P}_{\mathrm{v}}\right)\right]\right.
\end{aligned}
$$

or

$$
\begin{aligned}
& \rho\left(\mathrm{A}^{-1} \mathrm{Pu}, \mathrm{A}^{-1} \mathrm{Pv}\right) \leq \frac{1}{\alpha-1}\left[\rho\left(\mathrm{A}^{-1} \mathrm{Pu}, \mathrm{Pu}\right)+\rho\left(\mathrm{A}^{-1} \mathrm{Pv}, \mathrm{Pv}\right)\right] \\
& \leq \frac{1}{\alpha(\alpha-1)}[\rho(\mathrm{APu}, \mathrm{Pu})+\rho(\mathrm{APv}, \mathrm{Fv})] \\
& \leq \frac{\gamma}{\alpha(\alpha-1)}[\rho(\mathrm{Au}, \mathrm{Pu})+\rho(\mathrm{Av}, \mathrm{Pv})] \\
& \leq \frac{\beta \gamma}{\alpha(\alpha-1)}\left[\rho\left(\mathrm{u}, \mathrm{A}^{-1} \mathrm{Pu}\right)+\rho\left(\mathrm{v}, \mathrm{A}^{-1} \mathrm{Pv}\right)\right]
\end{aligned}
$$

By condition (iii), $q=\frac{\beta \gamma}{\alpha(\alpha-1)} \leq 1 / 2$. Therefore, by Kannan's criterion, $A^{-1} P$ will have a unique fixed point $u^{*}$ (say). To find the error estimates, we note that

$$
\begin{aligned}
\rho\left(u_{n}, u^{*}\right) & =\rho\left(A^{-1} P_{n-1}, A^{-1} P u^{*}\right) \\
& \leq q\left[\rho\left(u_{n-1}, A^{-1} P u_{n-1}\right)+\rho\left(u^{*}, A^{-1} P u^{*}\right)\right] \\
& =q \rho\left(u_{n-1}, A^{-1} P u_{n-1}\right) \\
& \leq q\left(\frac{q}{1-q}\right)^{n-1} \rho\left(u_{0}, A^{-1} P u_{0}\right)
\end{aligned}
$$

Since $0<q<1 / 2,0<\frac{q}{1-q}<1$, so that $u_{n}$ converges to the unique solution of the given equation as $\mathrm{n} \rightarrow \infty$.

The above inequality gives the apriori error estimate.

We next consider the equation $A^{n} u=P^{m} u$, where $u \in R$ and $n$ and $m$ are positive integers $(n \geq m)$. A and $P$ are the same as prescribed earlier.

THEOREM 2.2. Let the following conditions be fulfilled for all $u, v \in R$,

(i) $\beta \rho(u, v) \geq \rho(A u, A v) \geq \alpha \rho(u, v), \quad \beta>\alpha>1$;

(ii) $\rho(\mathrm{APu}, \mathrm{Pu}) \leq \gamma \rho(\mathrm{Au}, \mathrm{Pu})$;

(iii) $\mathrm{A}$ and $\mathrm{P}$ commute;

(iv) $2 \beta \gamma<\alpha(\alpha-1)$.

Then the sequence $\left\{u_{i}\right\}$ defined by

$$
\mathrm{A}^{\mathrm{n}} \mathrm{u}_{\mathrm{i}+1}=\mathrm{P}^{\mathrm{m}} \mathrm{u}_{\mathrm{i}}
$$


where $u_{0}$ prechosen, $n$ and $m$ positive integers and $n \geq m, i=0,1,2, \ldots$, will converge to the unique solution $u^{*}$ of the equation $A^{n} u=P^{m}$. The error estimate is given by

$$
\rho\left(u_{i}, u^{*}\right) \leq \frac{q}{\alpha^{i p}}\left(\frac{q}{1-q}\right)^{i m-1} \rho\left(u_{o}, A^{-1} P_{o}\right)
$$

PROOF. Let $n=m+p$, where $p$ is a positive integer. Hence, sequence $\left\{u_{i}\right\}$ is expressed by

$$
\mathrm{A}^{\mathrm{n}} \mathrm{u}_{\mathrm{i}+1}=\mathrm{P}^{\mathrm{m}} \mathrm{u}_{\mathrm{i}}
$$

or

$$
A^{n-1} u_{i+1}=A^{-1} P^{m} u_{i}
$$

Hence,

$$
\begin{aligned}
u_{i+1} & =\left(A^{-1}\right)^{n} P^{m} u_{i} \\
& =\left(A^{n}\right)^{-1} P^{m} u_{i}
\end{aligned}
$$

Since $A^{-1}$ exists and $A$ commutes with $P$, we have $A^{-1} P=P A^{-1}$, so that $A^{-1}$ commutes with $\mathrm{P}$.

Therefore,

$$
\begin{aligned}
& \left(A^{n}\right)^{-1} P^{m}=\left(A^{-1}\right)^{p}\left(A^{-1}\right)^{m} P^{m}
\end{aligned}
$$

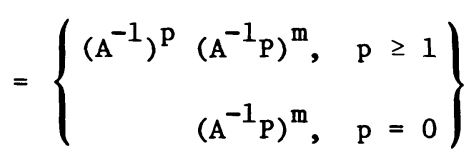

Hence,

$$
u_{i+1}=\left(A^{-1}\right)^{p}\left(A^{-1} P\right)^{m} u_{i}
$$

Now proceeding as in the previous theorem, we prove that $A^{-1} P$ will have a unique fixed point $u^{*}$ (say).

Thus

$$
\mathrm{u}^{*}=\mathrm{A}^{-1} \mathrm{P} \mathrm{u}^{*}
$$

and so

$$
\left(A^{-1} P\right)^{m} u^{*}=u^{*}
$$

Therefore, $u^{*}$ is also a fixed point of $\left(A^{-1} P\right)^{m}$. To prove that $u^{*}$ is the unique fixed point of $\left(A^{-1} P\right)^{m}$, we proceed as follows.

If possible, let $v^{*}$ be another fixed point of $\left(A^{-1} P\right)^{m}$ such that $v^{*} \neq u^{*}$. Then,

$$
\begin{aligned}
\rho\left(u^{*}, v^{*}\right) & =\rho\left(\left(A^{-1} P\right)^{m} u^{*},\left(A^{-1} P\right)^{m} v^{*}\right) \\
& \leq q\left[\rho\left(\left(A^{-1} P\right)^{m} u^{*},\left(A^{-1} P\right)^{m-1} u^{*}\right)+\rho\left(\left(A^{-1} P\right)^{m} v^{*},\left(A^{-1} P\right)^{m-1} v^{*}\right)\right]
\end{aligned}
$$




$$
\begin{aligned}
& \leq \frac{q}{1-q} \rho\left(\left(A^{-1} P\right)^{m} v^{*},\left(A^{-1} P\right)^{m-1} v^{*}\right) \\
& \leq q\left(\frac{q}{1-q}\right)^{m-1} \rho\left(v^{*}, A^{-1} P v^{*}\right) \\
& =q\left(\frac{q}{1-q}\right)^{m-1} \rho\left(\left(A^{-1} P\right)^{m} v^{*},\left(A^{-1} P\right)^{m+1} v^{*}\right) \\
& \leq q\left(\frac{q}{1-q}\right)^{2 m-1} \rho\left(v^{*},\left(A^{-1} P\right) v^{*}\right) \\
& \leq q\left(\frac{q}{1-q}\right)^{i m-1} \rho\left(v^{*},\left(A^{-1} P\right) v^{*}\right), \quad i=1,2,3, \ldots \\
& \longrightarrow 0, i \rightarrow \infty, 0<\frac{q}{1-q}<1
\end{aligned}
$$

Since $\mathrm{A}$ is an onto mapping, $\mathrm{A}^{-1}$ exists and is continuous and is also an onto mapping. Furthermore, it follows from (i) that $\left(\mathrm{A}^{-1}\right)^{\mathrm{p}}$ is a contraction mapping and hence has a unique fixed point in $R$.

Since $\left(A^{-1}\right)^{p}$ and $\left(A^{-1} P\right)^{m}$ commute and since each of them has unique fixed points, it follows that $\left(A^{-1}\right)^{p}\left(A^{-1} P\right)^{m}$ has a unique fixed point $u^{*}$ (say). Now,

$$
\begin{aligned}
\rho\left(u_{i}, u^{*}\right) & =\rho\left(\left(A^{-1}\right)^{p}\left(A^{-1} P\right)^{m} u_{i-1},\left(A^{-1}\right)^{p}\left(A^{-1} P\right)^{m} u^{*}\right) \\
& \leq \frac{1}{\alpha^{p}} \rho\left(\left(A^{-1} P\right)^{m} u_{i-1},\left(A^{-1 P}\right)^{m} u^{*}\right) \\
& \leq \frac{q}{\alpha^{i p}}\left(\frac{q}{1-q}\right)^{m i-1} \rho\left(u_{o}, A^{-1} P u_{o}\right)
\end{aligned}
$$

which shows that $u_{i} \rightarrow u *$ as $i \rightarrow \infty$.

THEOREM 2.3. Let $R$ be a metric linear space. Let the following conditions exist:

(i) $B \rho(u, v) \geq \rho(A u, A v) \geq \alpha \rho(u, v), \alpha>0$ for all $u, v \in R$;

(ii) $\quad\left(\left(A^{-n} P^{m}\right)^{\lambda} u, \theta\right) \leq k \rho(u, \theta)$ for all positive integers $\lambda$;

(iii) $A^{-n} P^{m}$ is continuous at its fixed point;

(iv) $\mathrm{A}$ and $\mathrm{P}$ commute;

(v) $P$ is compact and $P^{\mu}$ is closed for all finite positive integers $\mu$;

(vi) $\rho\left(\left(\mathrm{A}^{\mathrm{n}}\right)^{\nu} \mathrm{u},\left(\mathrm{P}^{\mathrm{m}}\right)^{\nu} \mathrm{u}\right) \geq \rho\left(\mathrm{A}^{\mathrm{n}} \mathrm{u}, \mathrm{P}^{\mathrm{m}} \mathrm{u}\right)$ for all finite positive integers $\nu$.

Then the sequence $\left\{u_{i}\right\}$ difined by $A^{n} u_{i+1}=P^{m} u_{i}$ ( $u_{0}$ prechosen, $n$ and $m$ are positive integers and $n<m, i=0,1,2, \ldots$ ) will converge to a solution $u^{*}$ of the equation $A^{n} \mathrm{u}=\mathrm{P}^{\mathrm{m}} \mathrm{u}$.

PROOF. The sequence $\left\{u_{i}\right\}$ expressed by 


$$
u_{i}=A^{-n} P^{m} u_{i-1}=\left(A^{-n} P^{m}\right)^{i} u_{0}, \quad i=0,1,2, \ldots
$$

is we11-defined. Let us denote $A^{-n^{m}}$ by $G$.

Since $\mathrm{R}$ is a metric linear space, the null element also belongs to $\mathrm{R}$.

By condition (ii)

$$
\rho\left(u_{i}, \theta\right)=\rho\left(\left(A^{-n_{P} m}\right)^{i} u_{o}, \theta\right) \leq k \rho\left(u_{o}, \theta\right)
$$

which implies that $\left\{u_{i}\right\}$ is bounded.

Since $P$ is compact and $\left\{u_{i}\right\}$ is bounded, $\left\{\mathrm{Pu}_{i}\right\}$ is sequentially compact and is hence bounded. Thus, $\left(P\left(\mathrm{Pu}_{i}\right)\right)$ is again compact, so that $\mathrm{P}^{2}$ is compact. In general, $\mathrm{P}^{\mathrm{m}}$ is compact with $\mathrm{m}$ a positive integer.

Since $\left\{u_{i}\right\}$ and $A^{-1}$ are both bounded, $\left\{\left(A^{n}\right)^{-1} u_{i}\right\}$ is also bounded. Since $P^{m}$ is compact and $A^{-1}$ commutes with $P^{m},\left\{\left(A^{n}\right)^{-1} P^{m} u_{i}\right\}$ is compact, $i=0,1,2, \ldots$. Thus $\left\{u_{i}\right\}$ defined by $u_{i}=G u_{i-1}, i=0,1,2, \ldots$, contains a convergent subsequence $\left\{u_{i p}\right\}$ (Say).

Let $u_{i p} \rightarrow u^{*}$ as $p \rightarrow \infty$.

Now $u_{i_{p}}^{p}=G^{k} u_{i}$ for some integer $k$.

Thus $G^{k} u_{i(p-1)} \rightarrow u^{*}$ as $p \rightarrow \infty$, for finite $k$.

Since $A^{-1}$ and $P$ commute,

Since $A^{-1}$ is continuous,

$$
G^{k} u_{(p-1)}=\left(A^{-1} P\right)^{k} u_{(p-1)}=\left(A^{-1}\right)^{k} u_{(p-1)}
$$

$$
\lim _{p \rightarrow \infty}\left(A^{-1}\right)^{k} u_{i p}=\left(A^{-1}\right)^{k} u^{*}
$$

$\mathrm{P}^{\mu}$ being closed $\mathrm{x}$ for all finite positive integers $\mu$, we obtain from above that

$$
u *=P^{k}\left(A^{-1}\right)^{k} u *=G^{k} u *
$$

Thus, $u *$ is a solution of $A^{n k} u=P^{m k} u$.

By virtue of condition ( $v i$ ), $u^{*}$ is also a solution of $A^{n} u=P^{m} u$.

Now, $G$ being continuous at its fixed points,

$$
\lim _{\mathrm{p} \rightarrow \infty} \mathrm{u}_{\mathrm{i}_{\mathrm{p}+1}}=\lim _{\mathrm{p} \rightarrow \infty} \mathrm{Gu}_{\mathrm{i}_{\mathrm{p}}}=\mathrm{Gu} *=\mathrm{u} *
$$

Therefore $\left\{u_{i}\right\}$ converges to $u^{*}$, a solution of the given equation.

3. AN EXAMPLE.

Let

$$
u(x) \in C(0,1)
$$




$$
\begin{aligned}
& A u=u^{2}(x)+2(x+15) u(x)-1.5 ; \\
& D(A) ; \quad 0.05 \leq u(x) \leq 1.5 \\
& P u=7 \int_{0}^{1}|x-t|\left[u(t)-\frac{u^{2}(t)}{8}\right] d t \\
& D(P): 0.06 \leq u(x) \leq 0.13
\end{aligned}
$$

We are interested in the solvability of the integral equation $\mathrm{Au}=\mathrm{Pu}$. We have

$$
\begin{aligned}
\mathrm{Pu} & =7 \int_{0}^{1}|\mathrm{x}-\mathrm{t}|\left[\mathrm{u}(\mathrm{t})-\frac{\mathrm{u}^{2}(\mathrm{t})}{8}\right] \mathrm{dt} \\
& \geq 7 \int_{0}^{1}|\mathrm{x}-\mathrm{t}|\left[0.06-\frac{(0.13)^{2}}{8}\right] \mathrm{dt} \\
& =0.133\left[1-2 \mathrm{x}+2 \mathrm{x}^{2}\right]
\end{aligned}
$$

Since $\operatorname{Min}_{0 \leq x \leq 1}\left[1-2 x+2 x^{2}\right]=1 / 2$

$$
\mathrm{Pu} \geq 0.067 \text { for } \mathrm{u} \in \mathcal{D ( P )} \text {. }
$$

Again

$$
\begin{aligned}
P u & =7 \int_{0}^{1}|x-t|\left[u(t)-\frac{u^{2}(t)}{8}\right] d t \\
& \leq 7\left(0.13-\frac{(0.06)^{2}}{8}\right) \int_{0}^{1}|x-t| d t \\
& \leq \frac{7 \times 0.13}{2}\left(1-2 x+2 x^{2}\right) \\
& =1.365 \text { for } u \in D(P)
\end{aligned}
$$

Thus we have $0.067 \leq \mathrm{Pu} \leq 1.365$ for all $\mathrm{u} \in D(\mathrm{P})$ and hence $D(\mathrm{~A}) \supseteq R(\mathrm{P})$.

We now introduce in $D(A)$ the $L_{2}(0,1)$ norm (i.e. ||$u \|^{2}=\int_{0}^{1} u^{2} d x$ for a11 u $\in D(A)$ ) and complete $D(A)$ with respect to the above \|\| . Since $D(A)$ being now a subspace of $\mathrm{L}_{2}(0,1)$, we can introduce the scalar product $(\mathrm{u}, \mathrm{v})=\int_{0}^{1} \mathrm{uv} \mathrm{dx}, \mathrm{u}, \mathrm{v} \in D(A)$ and $\|\mathrm{u}\|^{2}=(\mathrm{u}, \mathrm{v})$.

On the choice of the metric $\rho(\mathrm{u}, \mathrm{v})=\|\mathrm{u}-\mathrm{v}\|$ for $\mathrm{all} \mathrm{u}, \mathrm{v} \in D(\mathrm{~A}), D(\mathrm{~A})$ becomes a complete metric space.

Since A is a continuous operator, $R(A)$ is closed.

We further assume that

$$
0.093 \leq|| u(x)|| \leq 0.13 \text { for all } u \in D(P) .
$$

Now for all $\mathrm{u} \in \mathcal{D ( A )}$ 


$$
\begin{aligned}
(A u-A v, u-v) & =2 \int_{0}^{1}(x+15)(u-v)^{2} d x+\int_{0}^{1}(u+v)(u-v)^{2} d x \\
& \geq 30 \int_{0}^{1}(u-v)^{2} d x+\int_{0}^{1}[u(x)+v(x)](u-v)^{2} d x \\
& =30 \int_{0}^{1}(u-v)^{2} d x+[u(\xi)+v(\xi)] \int_{0}^{1}(u-v)^{2} d x \text { where } 0<\xi<1 \\
& \geq(30+2 \times 0.05)|| u-v \|^{2} \\
& =30.1\|u-v\|^{2}
\end{aligned}
$$

Thus we have $\quad \alpha=30.1$.

$$
\begin{aligned}
D(A) & : 0.05 \leq u(x) \leq 1.5 \\
A u & =u^{2}(x)+2(x+15) u(x)-1.5 \\
& \geq(0.05)^{2}+2.15 \times 0.05-1.5 \\
& =0.0025
\end{aligned}
$$

Also

$$
\begin{aligned}
A u & =u^{2}(x)+2(x+15) u(x)-1.5 \\
& \leq(1.5)^{2}+2(1+15) 1.5-1.5 \\
& =48.75 .
\end{aligned}
$$

Hence

$$
R(\mathrm{~A}): 0.0025 \leq \mathrm{Au} \leq 48.75 \text {. }
$$

Thus

$$
D(A) \subseteq R(A) \text {. }
$$

By (3.6), A has a bounded inverse for all u $\in D(A)$.

Since $R(P) \subseteq D(A) \subseteq R(A), A^{-1} \mathrm{Pu}$ is well defined and the sequence $u_{n+1}=A^{-1} P_{n}$, $\mathrm{n}=0,1,2, \ldots$ is also well-defined. Moreover,

$$
\begin{aligned}
\|A u-A v\| & =\|(u-v)[2(x+15)+(u+v)]\| \\
& \leq[2|| x+15||+|| u||+|| v||]|| u-v|| \text { for all u,v } \in D(A) .
\end{aligned}
$$

Now,

$$
\|x+15\|^{2}=\int_{0}^{1}(x+15)^{2} d x=240.333
$$

and hence

$$
\begin{aligned}
\|\mathrm{x}+15\| & =15.503 \\
\|\mathrm{Au}-\mathrm{Av}\| & \leq(2 \times 15.503+1.5+1.5)\|\mathrm{u}-\mathrm{v}\| \\
& =34.006|| \mathrm{u}-\mathrm{v} \|
\end{aligned}
$$

so that we take

$$
\beta=34.006 \text {. }
$$

Now for all $u \in D(P)$, 


$$
\begin{aligned}
(A u, u) & =\int_{0}^{1}\left[u^{2}(x)+2(x+15) u(x)-1.5\right] u(x) d x \\
& =\int_{0}^{1} u^{3}(x) d x+2 \int_{0}^{1}(x+15) u^{2}(x) d x-1.5 \int_{0}^{1} u(x) d x \\
& \geq 2 \times 15 \int_{0}^{1} u^{2}(x) d x+0.06 \int_{0}^{1} u^{2}(x) d x-1.5\left(\int_{0}^{1} u^{2} d x\right)^{\frac{1}{2}}
\end{aligned}
$$

Hence,

$$
\|\mathrm{Au}\||| \mathrm{u}\|\geq 30\| \mathrm{u}\left\|^{2}+0.06|| \mathrm{u}\right\|^{2}-1.5\|\mathrm{u}\| \text {. }
$$

Using the lower bound for ||$u||, u \in D(P)$,

$$
\begin{aligned}
|| \mathrm{Au} \| & \geq 30.06|| \mathrm{u}||-1.5 \\
& \geq 30.06 \times 0.093-1.5 \\
& =1.2956 \simeq 1.30
\end{aligned}
$$

Again

$$
\begin{aligned}
|| \mathrm{Pu}||^{2} & =49 \int_{0}^{1}\left[\int_{0}^{1}|\mathrm{x}-\mathrm{t}|\left(\mathrm{u}(\mathrm{t})-\frac{\mathrm{u}^{2}(\mathrm{t})}{8}\right) \mathrm{dt}\right]^{2} \\
& \leq 49\left(0.13+\frac{(0.06)^{2}}{8}\right)^{2} \int_{0}^{1}\left[\int_{0}^{1}|\mathrm{x}-\mathrm{t}| \mathrm{dt}\right]^{2} \mathrm{dx} \\
& =0.83939 \times \frac{7}{60}=0.097288
\end{aligned}
$$

Hence, || $\mathrm{Pu} \| \leq 0.311$.

Using the above result, we have for $u \in D(P)$ that

$$
|| \mathrm{Au}-\mathrm{Pu}|| \geq|| \mathrm{Au}||-|| \mathrm{Pu}|| \geq(1.30-0.311)=0.989 \text {. }
$$

Now

$$
\begin{aligned}
\mathrm{APu}-\mathrm{Pu} . & =(\mathrm{Pu})^{2}+2(\mathrm{x}+15) \mathrm{Pu}-\mathrm{Pu}-1.5 \\
& =(\mathrm{Pu})^{2}+(2 \mathrm{x}+29) \mathrm{Pu}-1.5
\end{aligned}
$$

Hence,

$$
\begin{aligned}
\|\mathrm{APu}-\mathrm{Pu}\| & \leq\|\mathrm{Pu}\|^{2}+\|2 \mathrm{x}+29\|\|\mathrm{Pu}\|+1.5 \\
& \leq 0.097+\left[\int_{0}^{1}\left(4 \mathrm{x}^{2}+4 \times 29 \mathrm{x}+29^{2}\right) \mathrm{dx}\right]^{1 / 2} \times 0.311+1.5 \\
& =0.097+\left(\frac{4}{3}+\frac{4 \times 29}{2}+29^{2}\right)^{1 / 2} \times 0.311+1.5 \\
& =10.930 .
\end{aligned}
$$

On choosing $\gamma=11.1$, we have

$$
|| A P u-P u|| \leq \gamma|| A u-P u|| \text { for all } u \in D(P)
$$

Now 


$$
\begin{aligned}
2 B \gamma & =2 \times 34.006 \times 11.1 \\
& =754.9332
\end{aligned}
$$

Again

$$
\begin{aligned}
\alpha(\alpha-1) & =30.1 \times 29.1 \\
& =875.91
\end{aligned}
$$

Thus,

$$
\frac{2 \beta \gamma}{\alpha(\alpha-1)}=\frac{754.9332}{875.91}=0.862<1
$$

Thus, all the assumptions of Theorem 2.1 are fulfilled so that the equation

$$
u^{2}(x)+2(x+15) u(x)-1.5=7 \int_{0}^{1}|x-t|\left[u(t)-\frac{u^{2}(t)}{8}\right] d t
$$

admits of a unique solution in the interval $0.06 \leq \mathrm{u}(\mathrm{x}) \leq 0.13$ for $0 \leq \mathrm{x} \leq 1$. Starting from $u_{0}=0.06 e^{x}$, the sequence of iterates $\left\{u_{n}\right\}$ is given by

$$
u_{n+1}^{2}(x)+2(x+15) u_{n+1}(x)-1.5=7 \int_{0}^{1}|x-t|\left[u_{n}(t)-\frac{u_{n}^{2}(t)}{8}\right] d t, \quad n=0,1,2, \ldots
$$

and the convergence of the sequence to the unique solution of the equation in $0.06 \leq \mathrm{u}(\mathrm{x}) \leq 0$ is assured.

For computational advantage, we can take $\left\{u_{n}^{\prime}\right\}$ as follows:

$$
\begin{aligned}
& u_{n}^{\prime}(x)=\frac{1}{2(x+15)}\left[1.5-u_{n-1}^{\prime 2}(x)+7 \int_{0}^{1}|x-t|\left[u_{n-1}^{\prime}(t)-\frac{u_{n-1}^{\prime 2}(t)}{8}\right] d t\right] . \\
& u_{0}^{\prime}(x)=0.06 e^{x} \\
& \left\{u_{n}^{\prime}(x)\right\} \text { will converge to the unique solution of the equation Au }=\text { Pu in the } \\
& \text { interval } 0.06 \leq u(x) \leq 0.13,0 \leq x \leq 1 .
\end{aligned}
$$

\section{REFERENCES}

1. KANNAN, R. Some results on fixed points, II, Amer. Math. Monthly 76 (1969), 405-408.

2. SEN, R. Approximate iterative process in a supermetric space, Bu11. Cal. Math. Soc. 63 (1971), 121-123.

3. CHATTERJEE, S.K. On a nonlinear functional equation, Mathematica Balkanica 2 (1972), 3-5.

4. CHAKRAVORTY, M. On solutions of certain functional equations, Bul1. Cal. Math. Soc. 71 (1978), 7-11. 


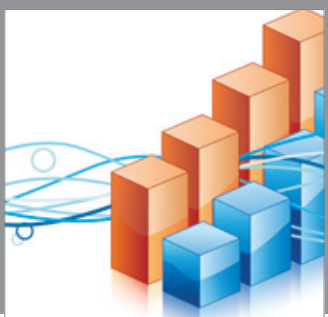

Advances in

Operations Research

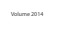

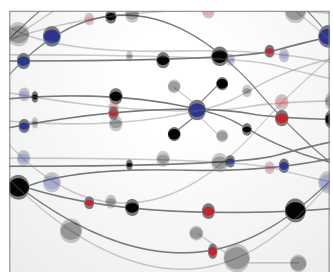

\section{The Scientific} World Journal
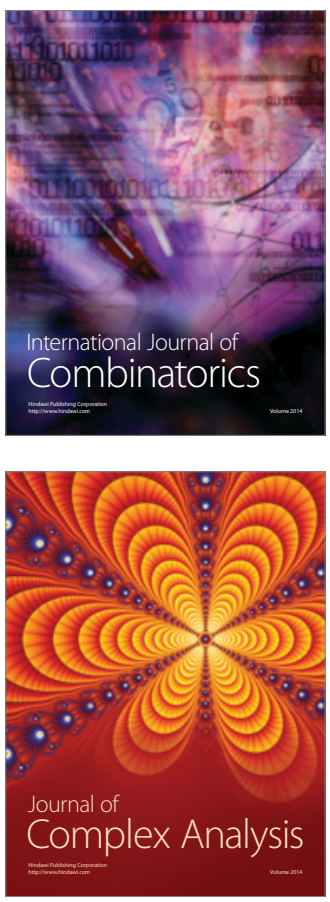

International Journal of

Mathematics and

Mathematical

Sciences
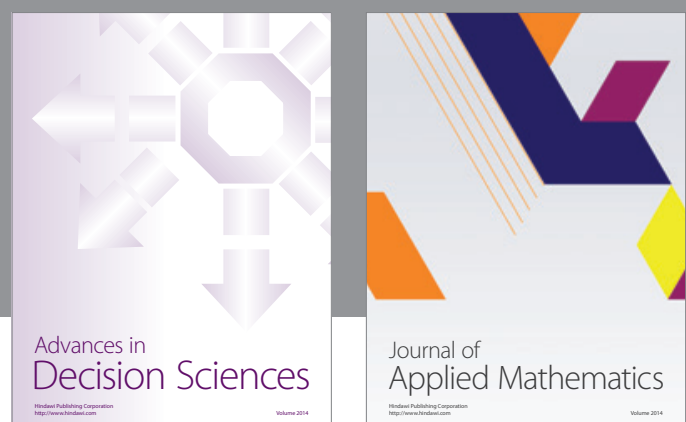

Journal of

Applied Mathematics
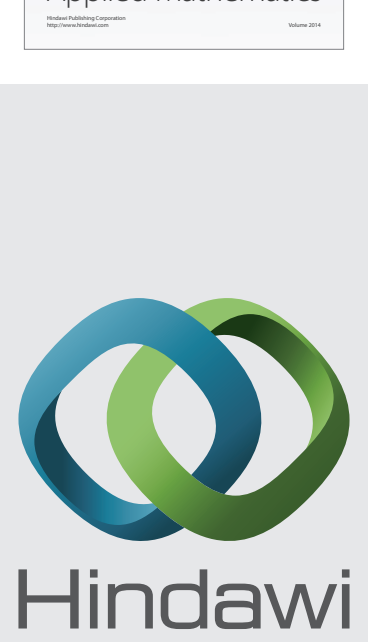

Submit your manuscripts at http://www.hindawi.com
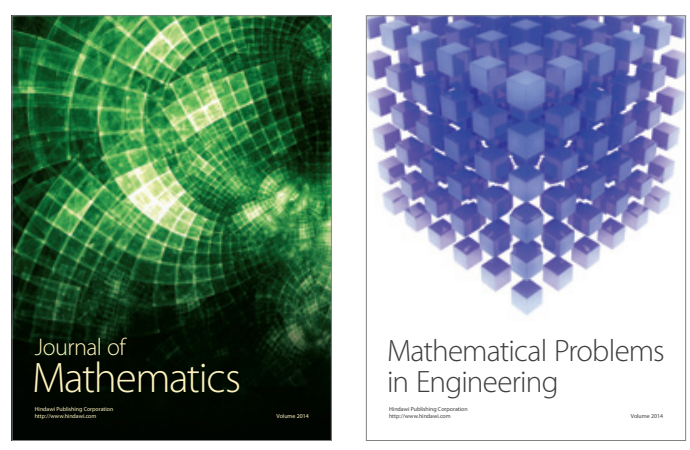

Mathematical Problems in Engineering
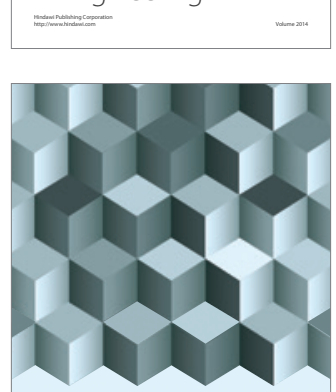

Journal of

Function Spaces
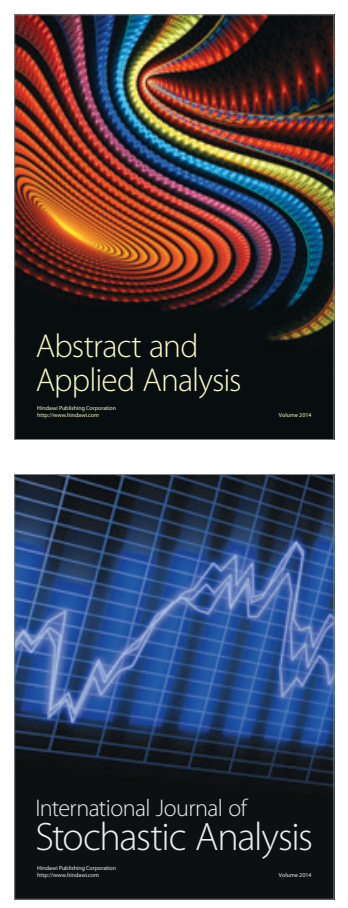

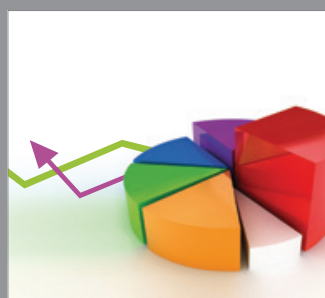

ournal of

Probability and Statistics

Promensencen
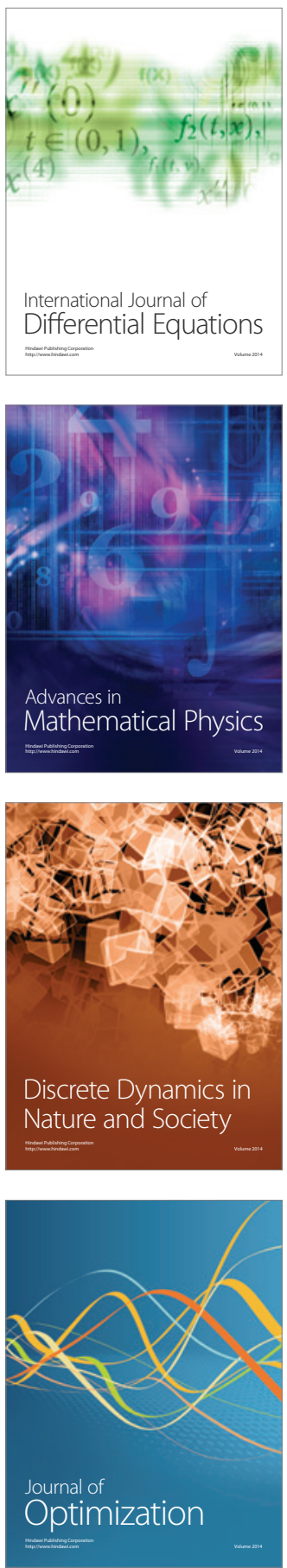